\title{
ILUMINAÇÃO SIMULADA OU AVALIADA, ESPECIFICAÇÃO DE SISTEMAS CONSTRUTIVOS E PERCEPÇÃO AMBIENTAL
}

\section{SIMULATED OR EVALUATED LIGHTING, SPECIFICATION OF CONSTRUCTIVE SYSTEMS AND ENVIRONMENTAL PERCEPTION}

\author{
Regina Coeli Ruschel ${ }^{1}$ \\ Universidade Estadual de Campinas, \\ Faculdade de Engenharia Civil, Arquitetura \\ e Urbanismo, \\ Campinas - SP \\ Editor Chefe \\ parc@fec.unicamp.br Letícia de Oliveira \\ Neves ${ }^{2}$ \\ Universidade Estadual de Campinas, \\ Faculdade de Engenharia Civil, Arquitetura \\ e Urbanismo, \\ Campinas - SP \\ Editor Chefe \\ leticia@fec.unicamp.br \\ Sidney Piochi Bernardini ${ }^{3}$ \\ Universidade Estadual de Campinas, \\ Faculdade de Engenharia Civil, Arquitetura \\ e Urbanismo, \\ Campinas - SP \\ Editor Chefe \\ sidpiochi@fec.unicamp.br \\ Daniel de Carvalho Moreira 4 \\ Universidade Estadual de Campinas, \\ Faculdade de Engenharia Civil, Arquitetura \\ e Urbanismo, \\ Campinas - SP \\ Editor Chefe \\ danmore@fec.unicamp.br
}

\section{Editorial}

A PARC Pesquisa em Arquitetura e Construção abre o primeiro número do Volume 9 de $2018 \mathrm{com}$ artigos de pesquisa desenvolvidos por pesquisadores dos estados brasileiros do Alagoas, da Bahia, de São Paulo, de Santa Catarina e do Rio Grande do Sul, incluindo interação internacional com Barcelona - Espanha. As instituições de ensino e pesquisa envolvidas nos estudos apresentados são: Faculdade Meridional, Faculdades de Itapiranga, Instituto Federal da Bahia, Universidade Comunitária da Região de Chapecó, Universidade de São Paulo, Universidade Federal de Alagoas, Universidade Federal de Santa Catarina, Universidade Regional Integrada do Alto Uruguai e das Missões e Universitat Politècnica de Catalunya. As áreas de formação dos autores concentram-se em Arquitetura e Urbanismo e Engenharia Civil. As temáticas abordadas abrangem a iluminação natural e artificial, a especificação em projeto de sistemas construtivos e a percepção ambiental.

O primeiro artigo deste volume da PARC - dos autores Pedro Oscar Pizzetti Mariano, Alice Theresinha Cybis Pereira e Carlos Verzola Vaz, da Universidade Federal de Santa Catarina - avalia elementos de fachada desenvolvidos a partir de regras de fractais lineares, sob o ponto de vista da iluminação natural. Segundo os autores, na literatura especializada ainda há poucos resultados sobre os efeitos da utilização dos padrões das geometrias fractais como elementos de controle solar. O trabalho foi realizado por meio de simulações paramétricas no programa Rhinoceros junto ao plugin Grasshopper, e diferentes métricas de iluminação natural foram analisadas através do plugin DIVA. Os resultados mostraram que a utilização das geometrias fractais pode contribuir positivamente para a iluminação natural do ambiente interno e para a ampliação do leque de alternativas para o design de componentes compositivos para fachadas.

Os autores Mônica Pereira Marcondes Cavaleri, Guilherme Reis Muri Cunha e Joana Carla Soares Gonçalves, da Universidade de São Paulo, analisam o desempenho em iluminação natural de um edifício de escritórios com planta profunda, localizado na cidade de São Paulo, de modo a definir a zona passiva de luz natural, considerando diferentes orientações solares e diferentes cenários de elementos de proteção solar. As análises foram realizadas por meio de simulações computacionais no programa Rhinoceros junto ao plugin DIVA,

\section{How to cite this article:}

RUSCHEL, Regina Coeli. et al. A iluminação simulada ou avaliada, a especificação de sistemas construtivos e a percepção ambiental. PARC Pesquisa em Arquitetura e Construção, Campinas, SP, v. 9, n. 1, p. 1-2, mar. 2018. ISSN 1980-6809. Disponível em:

<https://periodicos.sbu.unicamp.br/ojs/index.php/parc/article/view/8652469>. Acesso em: 17 maio 2018. doi:https://doi.org/10.20396/parc.v9i1.8652469.. 
sendo a métrica selecionada a Useful Daylight Illuminance (UDI). Pelos resultados, pôde-se observar a dificuldade em se obter $75 \%$ de UDI na área total do escritório, evidenciou-se a maior influência do elemento de sombreamento na zona periférica da planta, e quantificouse os efeitos da redução dos níveis luminosos nessa porção do ambiente, em consequência do sombreamento.

O artigo dos autores Júlia Silva de Moraes e Leonardo Salazar Bittencourt, da Universidade Federal de Alagoas, e Adrián Muros Alcojor, da Universidad Politécnica de Cataluña, comparam os indicadores de iluminação artificial presentes em normas e códigos brasileiros com os principais indicadores internacionais, através de uma pesquisa documental focada em ambientes residenciais. Os resultados indicam a falta de indicadores que melhor expressem o desempenho da iluminação artificial em ambientes residenciais, considerando as particularidades do local, tipologias construtivas, tecnologias disponíveis e atividades exercidas nos ambientes. Os indicadores nacionais mostraram-se genéricos, desconsiderando as especificidades das atividades exercidas em cada ambiente.

Claudivana Sistherenn Pagliari, Marcelo Fabiano Costella e Sílvio Edmundo Pilz - da Universidade Comunitária da Região de Chapecó - analisaram as especificações que estão sendo elaboradas por projetistas em termos da vida útil dos sistemas construtivos de edificações habitacionais. Foi realizada uma pesquisa de campo que envolveu levantamento com profissionais da área de projeto, a avaliação de projetos e memoriais, assim como a investigação das especificações por parte dos fabricantes de materiais como pisos, revestimentos internos e externos e impermeabilização. Constatou-se a carência de informações disponibilizadas dos materiais em termos de dados de durabilidade e vida útil, impossibilitando os projetistas de cumprirem suas premissas perante a norma de desempenho. O diagnóstico é regional, demandando replicação em outras regiões brasileiras.

O artigo de Gracielle Rodrigues da Fonseca Rech e Ângela do Valle, da Universidade Federal de Santa Catarina, e Bruna Cristina Lermen, da Universidade Regional Integrada do Alto Uruguai e das Missões, analisa o pátio de escolas públicas de ensino fundamental, segundo o ponto de vista do estudante. Utilizou-se três instrumentos de análise subjetiva - mapa comportamental, mapa cognitivo e poema dos desejos - de forma a identificar os aspectos que podem interferir no processo de apropriação destes espaços por parte das crianças usuárias. Identificou-se o pátio escolar como um lugar de socialização, de troca e de convívio, bem como de exploração e de experimentação sendo fundamental a participação dos usuários para melhor qualificar estes aspectos.

\section{Agradecimentos}

Agradecemos aos avaliadores pelo tempo despendido e valiosas considerações tecidas sobre os artigos submetidos.

\footnotetext{
${ }^{1}$ Regina Coeli Ruschel

Engenheira Civil. Doutor em Engenharia Elétrica e da Computação (UNICAMP). Livre Docente em Projeto Auxiliado por Computador (UNICAMP). Professora e Pesquisadora Colaboradora (FEC-UNICAMP) Endereço postal: Av. Albert Einstein, 951, Campinas, SP, Brasil, CEP 13.083-852.
}

${ }^{2}$ Letícia de Oliveira Neves

Arquiteta Urbanista. Doutora em Arquitetura, Tecnologia e Cidade pela Universidade Estadual de Campinas. Professora Doutora na Faculdade de Engenharia Civil, Arquitetura e Urbanismo da UNICAMP. Endereço postal: Av. Albert Einstein, 951, Campinas, SP, Brasil, CEP 13.083-852.

\section{${ }^{3}$ Sidney Piochi Bernardini \\ Arquiteto Urbanista. Doutor em Arquitetura e Urbanismo (FAU-USP). Professor Doutor na Faculdade de Engenharia Civil, Arquitetura e Urbanismo da UNICAMP. Endereço postal: Av. Albert Einstein, 951, Campinas, SP, Brasil, CEP 13.083-852.}

\footnotetext{
${ }^{4}$ Daniel de Carvalho Moreira

Arquiteto Urbanista. Doutor em Engenharia Civil (UNICAMP). Professor Doutor II na Faculdade de Engenharia Civil, Arquitetura e Urbanismo da UNICAMP. Endereço postal: Av. Albert Einstein, 951, Campinas, SP, Brasil, CEP 13.083-852.
} 